\title{
Dr Harold Merskey Award
}

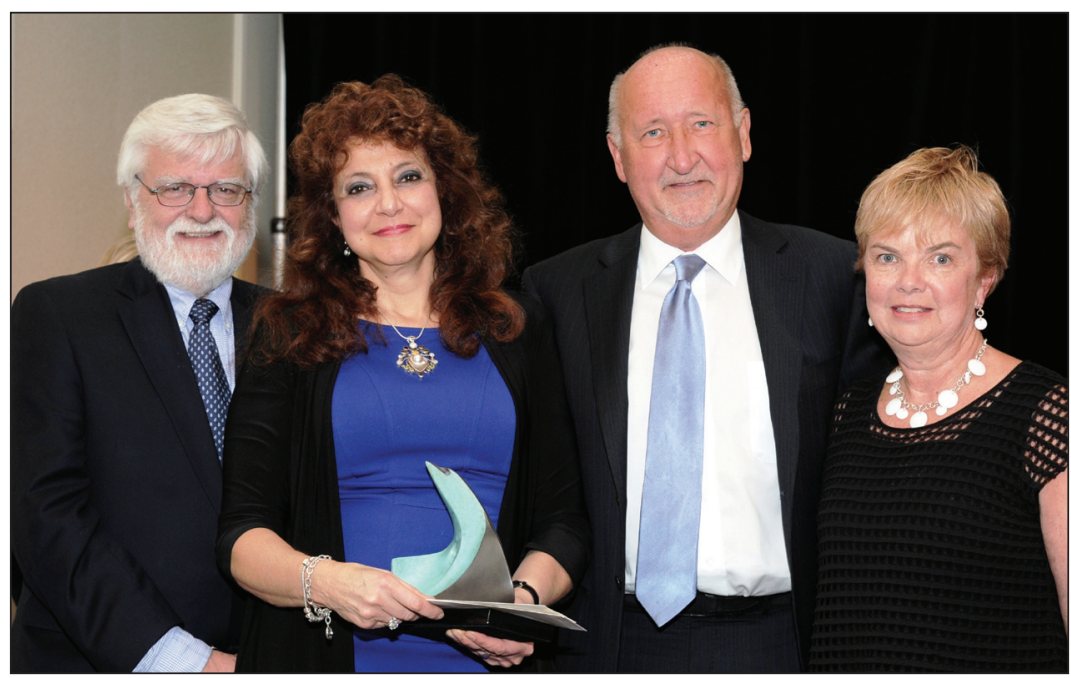

From left: Dr Kenneth Craig, Dr Angela Mailis-Gagnon, Robert B Kalina (Publisher, Pulsus Group) and Ann LeBlanc (Vice-President, Pulsus Group)

The winner of the 2013 Dr Harold Merskey Award is Dr Angela Mailis-Gagnon (University of Toronto, Toronto, Ontario) who, with her co-author Dr Paul Taenzer (University of Calgary, Calgary, Alberta), authored 'Evidence-based guideline for neuropathic pain interventional treatments: Spinal cord stimulation, intravenous infusions, epidural injections and nerve blocks' (Pain Res Manag 2012;17[3]:150-158). The award, consisting of $\$ 1,000$ and a piece of Canadian art, was presented during the Gala Dinner at the Annual Meeting of the Canadian Pain Society held in Winnipeg, Manitoba. 


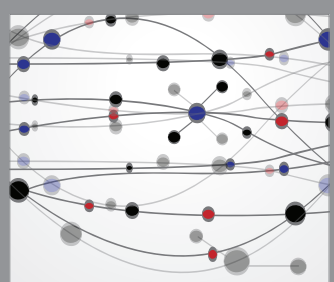

The Scientific World Journal
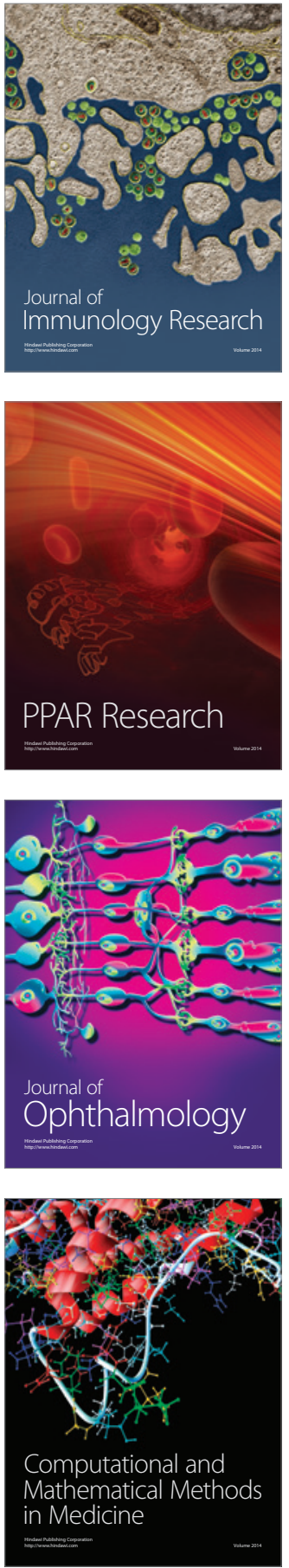

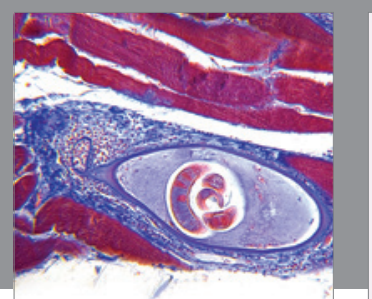

Gastroenterology Research and Practice

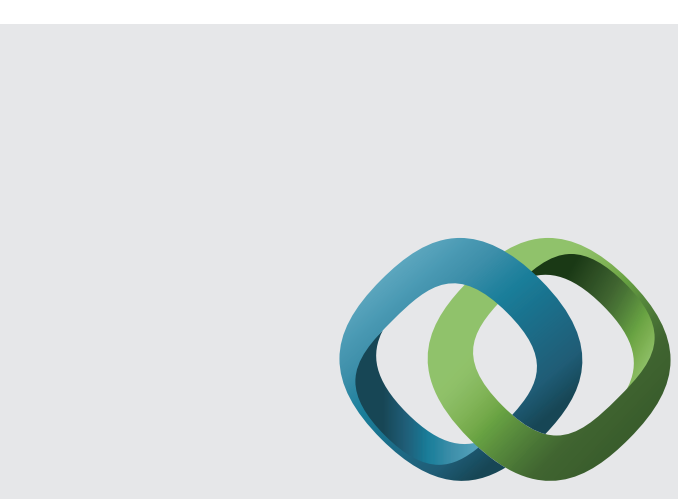

\section{Hindawi}

Submit your manuscripts at

http://www.hindawi.com
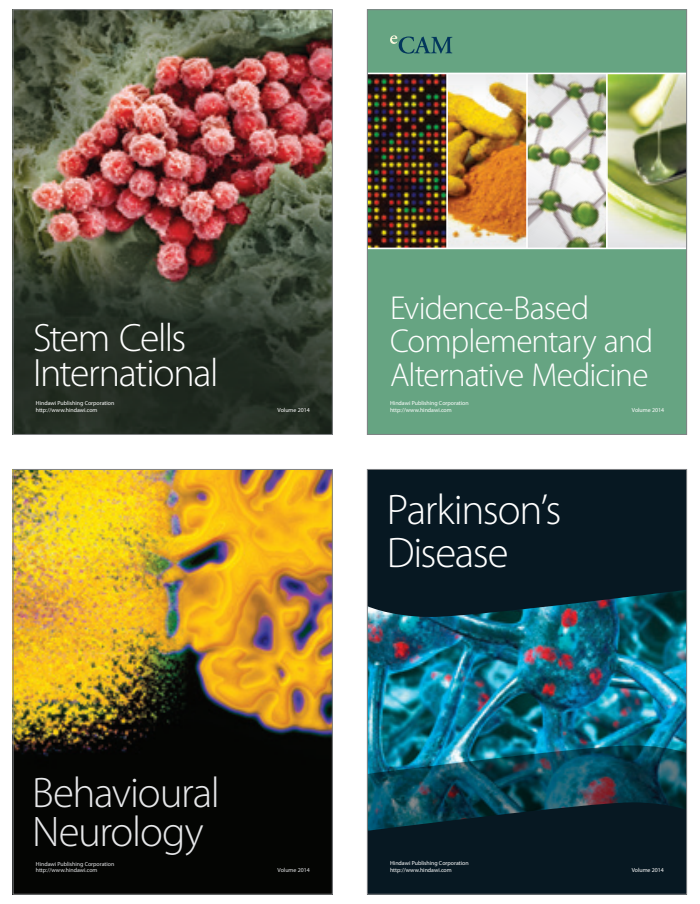
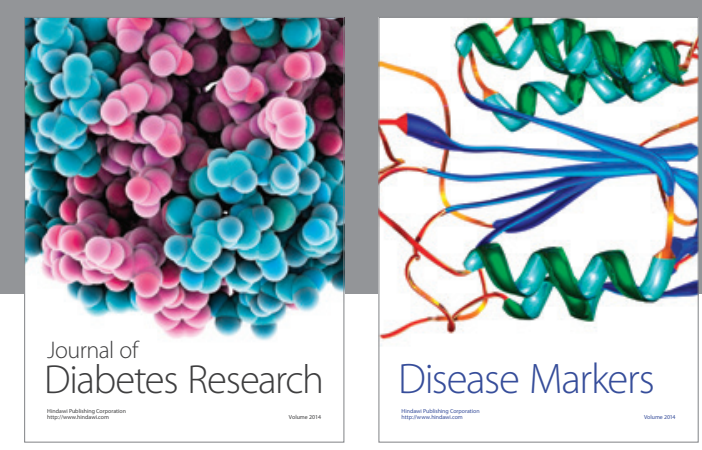

Disease Markers
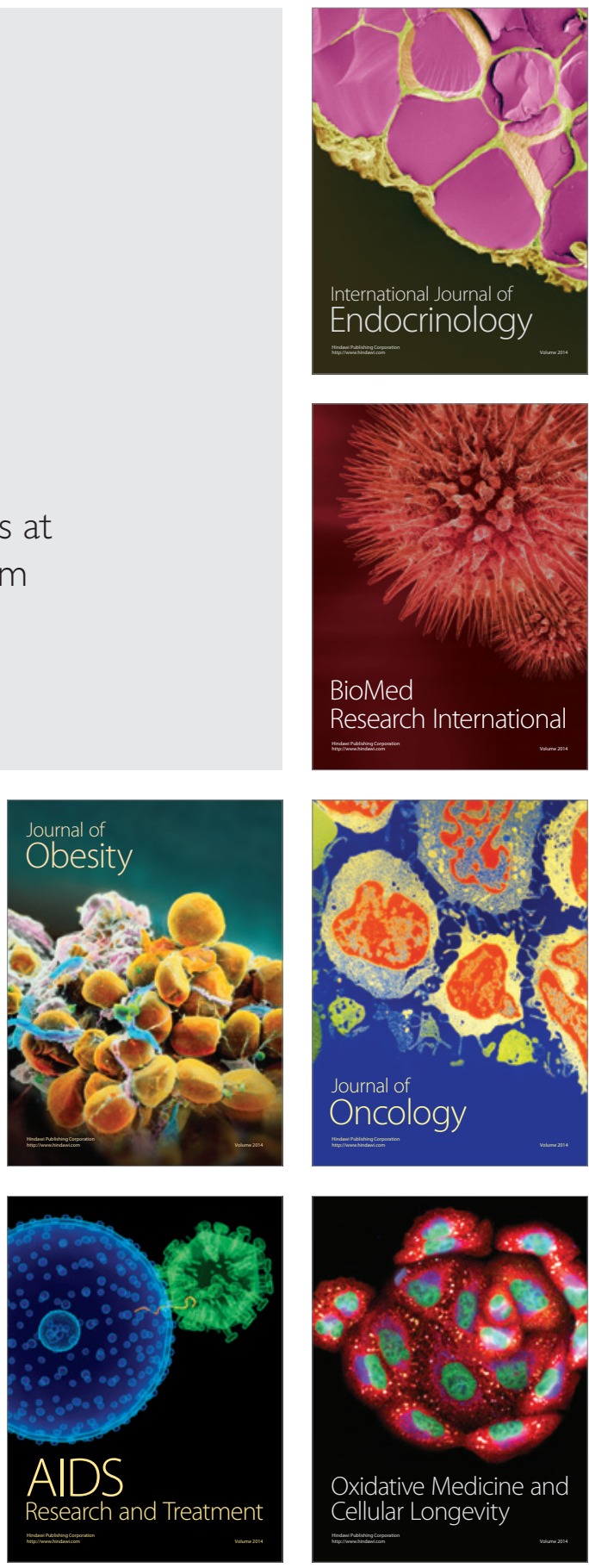